American Journal of Agricultural and Biological Sciences 6 (2): 242-248, 2011

ISSN 1557-4989

(C) 2011 Science Publications

\title{
Resistance to Citrus Canker in Key/Mexican Lime Induced by $\beta$-Aminobutyric Acid and Green Tea
}

\author{
${ }^{1}$ B. Beheshti, ${ }^{2}$ G.R. Sharifi-Sirchi, ${ }^{3}$ M. Mansouri, \\ ${ }^{4}$ A. Hosseinipour and ${ }^{5}$ N.L. Schlaich \\ ${ }^{1}$ Biotechnology Department, \\ ${ }^{2}$ Department of Agricultural Biotechnology, \\ ${ }^{3}$ Horticulture and Dates Research institute, \\ ${ }^{4}$ Department of Plant protection, College of Agriculture, \\ Shahid Bahonar University of Kerman, Kerman, Iran \\ ${ }^{5}$ Institute BioIII ,RWTH Aachen University, D-52056 Aachen, Germany
}

\begin{abstract}
Citrus bacterial canker, caused by Xanthomonas citri subsp. citri (Xcc), is a destructive disease. So far used chemicals to control this pathogen are either not effective or have harmful effects on the environment. To improve control of this disease, lime (Citrus aurantifolia) plants inoculated with $X c c$ were treated with $\beta$-Aminobutyric Acid (BABA), ascorbic acid (vitamin C), thiamin (vitamin $\mathrm{B} 1$ ), green tea (Camellia sinensis), copper oxychloride and distilled water. Lesion diameters of inoculated leaves were evaluated twenty days after treatment. The results showed that BABA and green tea had inhibitory effects on disease development. None of the agents used for plant treatment had direct antimicrobial activity on Xcc, except copper oxychloride. This indicated that the inhibitory effects of BABA and green tea resulted from strengthening the defense capacities of the plant. To support this claim, partial coding sequences of Pathogenesis-Related (PR) genes from lime were cloned and sequenced. Analysis of $P R$ gene expression showed increased mRNA levels of $\beta$-1,3-glucanase and chitinase, during disease development. Reduction in lesion size and lack of antimicrobial activity indicate that $\mathrm{BABA}$ and green tea might be useful treatments against $X c c$ infection.
\end{abstract}

Key words: Induced resistance, pathogenesis-related genes, plant activator, Xanthomonas. citri subsp. Citri, $\beta$-Aminobutyric Acid (BABA), Salicylic Acid (SA), Copper Ammonium Carbonate $(\mathrm{CAC})$, copper bacteriocides include, citrus canker, green tea

\section{INTRODUCTION}

Asiatic citrus canker, caused by the endophytic bacterium Xanthomonas citri subsp. Citri (Schaad et al., 2006) (Xcc) is a serious disease of commercial citrus varieties and some citrus relatives, distributed in widespread areas of the world (Goto, 1992). The pathogen causes lesions on leaves, twigs and fruits which later develop into white or yellow spongy pustules. These pustules then become darker and thicker and turn into brown corky cankers which are often surrounded by water-soaked margins. Severe infections can result in defoliation, badly blemished fruits, premature fruit drop, twig dieback and general tree decline (Rossetti, 1977; Stall and Seymour, 1983; Chand and Pal, 1982; Civerolo, 1981). Non-marketable quality due to lesions and premature fruit drop are the most economically important damages. Since all citrus cultivars are susceptible to canker, prevention, quarantines, control and eradication programs are the only tools available to control the disease, but come at a high annual cost for producers. Differences in susceptibility are mostly attributed to differences in stomata frequency and size (Goto, 1992). Stomata and wounds are Xcc's sites of entry into host plants. Within four days after entry, water soaked lesions appear on the infected tissue. A survey evaluated the effectiveness of thirteen bactericidal chemicals on three citrus species to control canker by spray application. In this study, Copper Ammonium Carbonate (CAC) with 8\% copper content was consistently the most effective agent in controlling Xcc (Mur et al., 1996). CAC is a contact poison and used to achieve adequate control on susceptible citrus hosts such as grapefruit and sweet orange (Graham et al., 2004; Schubert et al., 2001; Leite Jr et al., 1987). Disadvantages of long-term use of copper bacteriocides include induced copper resistance in xanthomonad populations (Marco and Stall, 1983;

Corresponding Author: G.R. Sharifi-Sirchi, Department of Agricultural Biotechnology, College of Agriculture,

Shahid Bahonar University of Kerman, Kerman, Iran Fax: +983413222043 
Rinaldi and Leite Jr, 2000) and accumulation of copper in the soil with potential phytotoxic and adverse environmental effects (Alva et al., 1995). However, other contact bacteriocides were not as effective as copper because they lack sufficient residual activity to protect leaf and fruit surfaces for extended periods (Graham et al., 2006; Rinaldi and Leite Jr, 2000; McGuire, 1988). Various synthetic and biological compounds are capable of controlling a large variety of plant diseases without displaying a direct antibiotic effect (Jakab et al., 2001). In recent years, the importance of vitamins as nutrients and as disease control agents has been emphasized (Pavet et al., 2005; Beyer et al., 2002). The objective of our study was the control of $X c c$ by use of new compounds with low adverse environmental effects. Moreover, we tested compounds that have systemic effects inside the plant which would be advantageous over contact bactericidal agents like copper containing compounds.

\section{MATERIALS AND METHODS}

Plant materials: Two year old lime juveniles were raised from seeds and used as plant material. They were maintained at $25-30^{\circ} \mathrm{C}$ and $60 \%$ relative humidity conditions in a greenhouse. The study was performed from 2005-2009.

Bacterial culture: Bacterial inoculum was prepared with Xcc strain $\mathrm{J} 1$ which we isolated from a lime leaf showing canker symptoms and confirmed by PCR using specific primer, XACF [CGTCGCAATACGATTGGAAC] and XACR [CGGAGGCATTGTCGAAGGAA] (Park et al., 2006). The bacterial strain was maintained by serial transfer on Nutrient Agar (NA) (Merck) and periodically reisolated from inoculations described below to maintain virulence. For greenhouse tests, the strain was grown in nutrient broth and incubated on a shaker at $28^{\circ} \mathrm{C}$ for $24 \mathrm{~h}$.

Inoculation and treatment of plants: To achieve high relative humidity, plants were covered with plastic bags one day prior to inoculation. All chemicals were purchased from Sigma-Aldrich Chemical Co. except for Green tea, which was obtained from the local market. Inoculum was prepared in a $0.85 \%(\mathrm{w} / \mathrm{v}) \mathrm{NaCl}$ solution, adjusted turbidometrically $(620 \mathrm{~nm})$ to approximately 107 cfu.ml-1 and infiltrated into the leaves by a needlefree syringe. Infected plants were treated by foliar spray application of $\beta$-Aminobutyric Acid (BABA) 250 ppm, vitamin C $1.5 \mathrm{mM}$, green tea (Camellia sinensis) $0.58 \%$ (w/v), copper oxychloride $0.6 \%$, vitamin B1 $50 \mathrm{mM}$, Salicylic Acid (SA) $2 \mathrm{mM}$ and for control distilled water, on the entire plant, one week after appearance of first symptoms. Lesion diameter evaluation was performed 20 days after chemicals treatment.
Inhibitory effect of treatments on Xcc in vitro: To determine direct antimicrobial activity of the different agents on Xcc, the well diffusion method was used (Rojas et al., 2006). Thus, $100 \mu \mathrm{L}$ cultured strain at a concentration of 107 cfu.ml-1 was added uniformly to cooled but still liquid Nutrient Agar. After solidification, wells were punched out of the agar and $100 \mu \mathrm{L}$ of each agent, adjusted to the above given concentration, was added into the wells. Distilled water served as a control. Plates were incubated at $28^{\circ} \mathrm{C}$ for 72 h. A clear growth-inhibition zone around the wells was measured as an indication for antimicrobial activity.

Total RNA extraction from lime leaves: Approximately 1-2 $\mathrm{g}$ of leaves were ground with a mortar and pestle in the presence of liquid nitrogen. The powder was transferred to a tube containing ice cold extraction buffer (100 mM Tris- $\mathrm{HCl} \mathrm{pH}$ 8.5/10 mM EDTA pH 8/100 mM LiCl/1\% SDS) and mixed. Trisequilibrated phenol was added, mixed before chloroform/isoamylalcohol was added and mixed. After centrifugation, the upper aqueous phase was extracted two times with chloroform/isoamylalcohol (24:1). Addition of $10 \mathrm{M} \mathrm{LiCl} 2$ to the supernatant precipitated the RNA over night. After centrifugation, the RNA pellet was resuspended in RNase-free $\mathrm{H} 2 \mathrm{O}$ and ethanol precipitated. The final RNA pellet was resuspended in RNase-free $\mathrm{H}_{2} \mathrm{O}$. RNA quantity and purity was analyzed by measuring the ratios of absorption at 260/280 and 260/230 nm and RNA integrity was evaluated from the $28 \mathrm{~S}$ and $18 \mathrm{~S}$ rRNA bands by ethidium bromide staining after agarose gel electrophoresis.

Preparation of cDNA: About $1 \mu \mathrm{g}$ total RNA was DNase treated and used to make cDNA. First-strand cDNA was prepared using RevertAid ${ }^{\mathrm{TM}}$ First Strand cDNA Synthesis Kit (Fermentas) according to the manufacturer's instructions.

Purification and cloning of cDNA fragment: Specific primers were used to amplify cDNA fragments, including: F (5'-AATGTTGCTAGCATTGTGACTCC3') and R (5'-GCAGCATTCAGAAACGCATCT-3') for Chitinase (CHI1) AF090336, F(5' TTCCGACGGATCGTTAAGTTACC-3') and R ( 5'CCACCCACTCTCTGATATCACG-3') for $\beta-1,3-$ Glucanase (GNSL) AJ000081, F (5'GGTCAGACTCGTGAGCATGC-3') and R (5'CATCGTACCTAGCCTTTGAGTACTTG-3') for Elongation factor 1-alpha (EF1) AY498567. The amplified fragments were excised from an agarose gel and purified with the AccuPrep PCR Purification Kit according to the manufacturer's instructions (Bioneer, South Korea). The purified DNA was ligated into the pTZ57R/T vector using InsT/A Clone ${ }^{\mathrm{TM}}$ PCR product Cloning Kit (Fermentas). The plasmids were 
transformed into competent $E$. coli cells. Recombinant plasmids were identified by colony PCR and purified plasmids confirmed by restriction enzyme digestion. The recombinant plasmids were extracted using the AccuPrep ${ }^{\circledR}$ Plasmid extraction Kit according to the manufacturer's instructions (Bioneer, South Korea).

DNA sequencing: Recombinant plasmids were sequenced in both directions by extending M13 reverse and forward primers, using the Automatic DNA Sequencer 3730Xl (Macrogene, Korea). The sequencer data were edited using Chromas software Version 1.41. The nucleotide sequence was analyzed using BLAST (Benson et al., 2002).

Expression analysis of $\beta$-1,3-glucanase and chitinase by semi quantitative PCR: Expression of a $\beta-1,3-$ glucanase and chitinase genes was analyzed by comparing the PCR band signals to the signals from the $E F 1$ gene. Each PCR reaction contained $0.5 \mu \mathrm{M}$ of each primer, $2 \mu \mathrm{L}$ of cDNA template and $10 \mu \mathrm{L}$ of $2 \mathrm{x}$ PCR Master Mix (Fermentas). Cycles were programmed as follows: The initial denaturing cycle at $94^{\circ} \mathrm{C}$ for $5 \mathrm{~min}$, followed by 35 cycles of denaturing at $94^{\circ} \mathrm{C}$ for $1 \mathrm{~min}$, annealing at $55^{\circ} \mathrm{C}$ for $1 \mathrm{~min}$ and elongation at $72^{\circ} \mathrm{C}$ for $2 \mathrm{~min}$, followed by a final cycle at $72^{\circ} \mathrm{C}$ for $7 \mathrm{~min}$. To define the optimal number of PCR cycles for exponential amplification, an aliquot from each of the samples was removed at 30 cycles thereafter at every fifth additional cycle. Expression was analyzed before and after inoculation and after treatment.

Statistical analysis: The experiment was arranged based on a Completely Randomized Design (CRD) with ten biological replicates. Ten leaves from each replicate were evaluated for necrotic lesion diameter and the mean of them used as each replication value. The means were compared for statistical significance using Duncan's multiple-range test $(\mathrm{p}=0.05)$.

\section{RESULTS}

We inoculated citrus leaves with $X c c$ and after first symptoms became visible attempted to reduce their spread by spray-treatment of the inoculated leaves with BABA $250 \mathrm{ppm}$, vitamin C $1.5 \mathrm{mM}$, green tea $0.58 \%$ (w/v), copper oxychloride $0.6 \%$, vitamin B1 $50 \mathrm{mM}$, SA $2 \mathrm{mM}$. Our results showed that spray treatment with green tea and BABA reduced lesion size by about 50\% as compared to the water control. Thus while watertreated leaves showed lesion sizes of about $1,2 \mathrm{~cm}$, BABA and green tea treated plants had lesions of only about $0,6 \mathrm{~cm}$. Treatments with vitamin $\mathrm{C}$ or vitamin B1 reduced lesion size by about $25 \%$. No significant reduction in lesion size was observed following treatment with copper oxychloride or salicylic acid (Fig. 1-2).

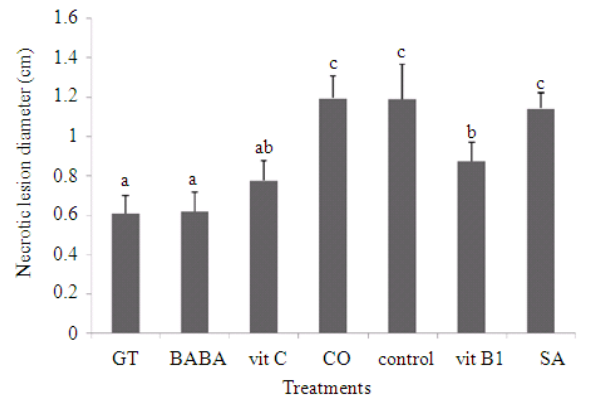

Fig 1: Suppressive effect of different treatments on necrotic lesion diameter caused by $X$. citri subsp. citri on lime leaves. Leaves of two years old juvenile were inoculated with $X c c$ and after appearance of symptoms treated with the various compounds. The lesion diameters were measured 20 days post application of the chemicals. GT: Green Tea $0.58 \%$ (w/v); BABA: $\beta$-aminobutyric acid 250 ppm; SA: salicylic acid $2 \mathrm{mM}$; Vit B1: Vitamin B1 50mM; Vit C: Vitamin C $1.5 \mathrm{mM}$; CO: Copper oxychloride $0.6 \%$. Different letters $(\mathrm{a}, \mathrm{b}, \mathrm{c})$ at each column denote significant differences between means $(p=0.05)$ according to Duncan's multiplerange test. The experiment was repeated three times

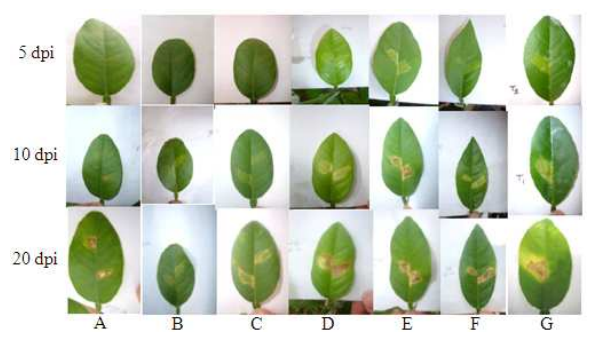

Fig. 2: Treated leaves with BABA and Green Tea showed smaller necrotic lesions then control and other treatments. Leaves were infected by injection with $1 \times 107$ cfu.ml-1 Xanthomonas citri subsp. citri. Leaves were photographed at the indicated times post chemical application . A; BABA; B, Green Tea; C, Vit C; D, Vit B1; E, Control; F, Salicylic acid; G, Copper Oxychloride. In order to test whether the reduction in lesion size was due to a direct growth-inhibitory effect of the applied agents, we tested their effect on the growth of Xcc in vitro. Thus, rapidly growing Xcc were embedded into nutrient agar plates into which holes were punched. Into these holes, $100 \mu \mathrm{L}$ of BABA, green tea, vitamin $\mathrm{C}$ and copper oxychloride were applied and the growth of Xcc was observed after over-night incubation. As can be seen in Fig. 3, only copper oxychloride had a direct growth-inhibiting effect on the bacteria, since all other compounds allowed uninhibited growth of the bacteria 


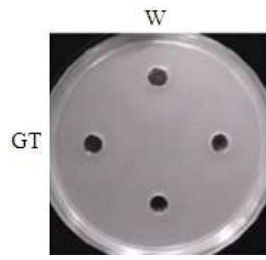

(a)

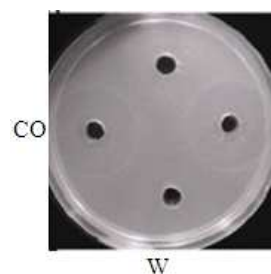

(c)

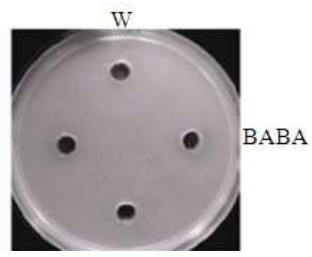

(b)

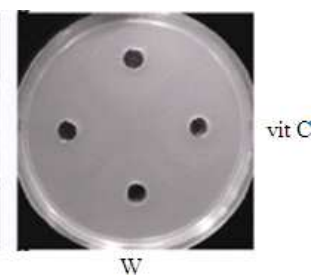

(d)
Fig. 3: Test for direct antimicrobial activity of the compounds suppressing lesion size. Rapidly growing $X c c$ bacteria were embedded in nutrient agar and incubated with the compounds indicated. Copper oxychloride showed antimicrobial activity against $X$. citri subsp. citri . Each compound was applied in two wells. GT; Green Tea, CO; Copper Oxychloride; w; distilled water, BABA; $\beta$-aminobutyric acid, Vit $\mathrm{C}$; vitamin $\mathrm{C}$. The observed reduced lesion size after green tea and BABA treatments prompted us to test whether enhanced physiological defense responses can be observed in the treated lime plants. Thus, we cloned by RT-PCR a 119 bp fragment of a $\beta$-1,3-glucanase and a $110 \mathrm{bp}$ fragment of a chitinase gene from lime (Fig.4)

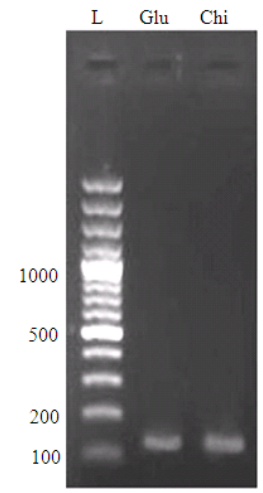

Fig. 4: RT-PCR bands of $\beta$-1,3-glucanase and chitinase genes of lime. Numbers to the left of photo show marker band sizes. L; ladder $3 \mathrm{~kb}$, Glu; $\beta$ 1,3-glucanase, Chi; chitinase. Sequencing the cloned PCR fragments allowed to align them with the sequences from orange. The alignment showed large regions of identity (Fig. 5), confirming that we cloned the correct pathogenesis-related genes

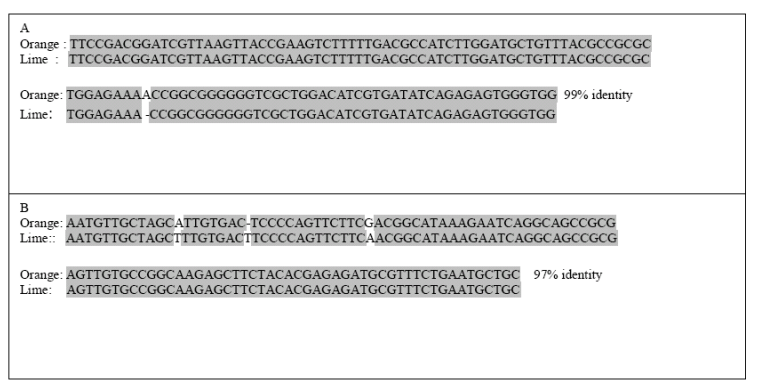

Fig. 5: Alignment of amplified lime (Citrus aurantifolia) cDNA with orthologous sequences from orange (Citrus sinensis). Two fragments (110bp for chitinase and $119 \mathrm{bp}$ for glucacanase) were amplified by RT-PCR from lime and sequenced. The obtained nucleotide sequence aligned with A) $>99 \%$ identity $\beta-1,3-$ glucanase and B) 97\% identity chitinase to the orthologous orange sequences. Using the same primers, we investigated the expression pattern of the two genes $24 \mathrm{~h}$ after infection with $X c c$ and a further $24 \mathrm{~h}$ after treatment with BABA or green tea by semi-quantitative reverse transcription PCR. As can be seen in Fig. 6, infection up-regulated glucanase expression. Further treatments did not appreciably influence expression of glucanase or chitinase

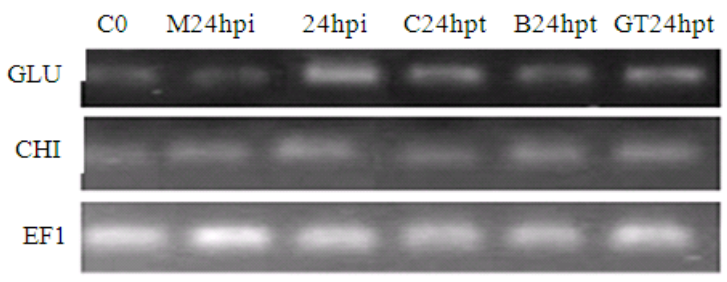

Fig. 6: Expression analysis of lime PR genes after Xcc inoculation and subsequent treatment with chemicals. Semi-quantitative reversetranscription PCR was used to compare the relative transcript amounts of the $P R$ genes $\beta-1,3-$ Glucanase (Glu) and Chitinase (Chi) after treatment of $X c c$-infected lime leaves with BABA and Green Tea. Glu; $\beta$-1,3-glucanase, Chi; chitinase, EF1; Elongation Factor 1-alpha, C0; control (time 0), M24hpI; non infected plant Mock $24 \mathrm{~h}$ post inoculation, 24hpI; Infected plants $24 \mathrm{~h}$ post inoculation, C24hpT; non treated Inoculated plant (control 3) $24 \mathrm{~h}$ post treatment; B24hpt; Treated plant with BABA $24 \mathrm{~h}$ post application, GT24hpt; Treated plant with Green Tea 24 h post application. Application of treatments were performed one weak after infection 


\section{DISCUSSION}

Citrus canker is a disease causing great economic damage to the afflicted regions. Effective treatments contain copper that limits its application to a few per year due to its general toxic effects. Our study aimed at identifying agents that do not have a general toxicity effect, yet limit pathogen damage on the plant. A function of vitamin B group in disease resistance has been described (Dong and Beer, 2000). Treatment with some members of vitamin B group protected tobacco (Nicotiana tabacum) and Arabidopsis plants from fungal and bacterial infections without inhibiting pathogen growth (Dong and Beer, 2000). Our results indicate that among the different treatments, BABA, green tea and vitamin $\mathrm{C}$ significantly reduced canker lesions in lime leaves. In vitro assays indicated that none of these agents had direct antimicrobial activity on Xcc confirming previous results (Cohen et al., 1999; Reuveni et al., 2003). Only copper oxychloride at $0.6 \%$ had a direct negative effect on the growth of the bacteria. Therefore, the reduced lesions obtained after $\mathrm{BABA}$ or green tea treatments cannot be explained by direct antimicrobial characteristics. We wondered whether $\mathrm{BABA}$ or green tea could raise the activation of a highly coordinated biochemical and structural defense system. The protection of plants from bacterial invasion by activation of the plant's defense system is an accepted concept (Lawton et al., 1996; Schroder et al., 1992). The mode of action of BABA in inducing resistance against $X c c$ is not yet fully understood. There are reports showing the induction of $P R$ genes after BABA treatment (Cohen, 1994). Green tea is full of components with anticancer, antiviral and anti pathogenic characters like polyphenols (catechins), fragrance components, amino acids (theanine), saponins and $\gamma$-aminobutyric acid (GABA). Thus, any of these constituents or a combination of them might induce increased pathogen defense. In plants, GABA accumulation was observed in response to biotic and abiotic stress (Roberts, 2007; Shelp et al., 1999). Here, we report for the first time a partial mRNA sequence of a $\beta$-1,3-glucanase and chitinase genes (PR) of lime. Analysis of the steadystate mRNA levels of these genes by semi-quantitative reverse transcription PCR showed that one $P R$ gene ( $\beta$ 1,3-glucanase) showed enhanced expression in response to $X c c$ infection (Fig. 6). We cannot see the reported effects of BABA on $P R-1$, chitinase and $\beta-1,3-$ glucanase accumulation in pepper, tomato and tobacco (Cohen, 1994; Cohen et al., 1994; Hwang et al., 1997). But understanding of the signaling pathways of BABA and green tea in resistance of lime to Xcc clearly deserve more investigation.

\section{CONCLUSION}

Application of $\mathrm{BABA}$ or green tea in citrus possesses promising potential in the control of the disease and could serve as an alternative to traditional chemical compounds which are harmful to the environment.

\section{REFERENCES}

Alejandro B., F. Juan, C. Cabrera, E. Ortega and M.A. Martinez-Tellez, 2009. Concentration and Physicochemical Properties of Chitosan Derivatives Determine the Induction of Defense Responses in Roots and Leaves of Tobacco (Nicotiana tabacum) Plants. Am. J. Agric. Biol. Sci., 4: 192-200.

Al-Quadan, F., H. Akel and R. Natshi, 2009. Characteristics of a novel highly thermostable and extremely thermophilic alkalitolerant amylase from hyperthermophilic bacillus strain HUTBS71. OnLine J. Biol. Sci., 9: 67-74.

Alshaebi, F., W. Yaacob, A. Samsudin and E. Alsabahi, 2009. Arsenic adsorption on bauxite mineral using batch equilibrium test. Am. J. Applied Sci., 6: 1826-1830.

Alva, A.K., J.H. Graham and C.A. Erson, 1995. Soil pH and copper effects on young 'Hamlin'orange trees. Soil Sci. Soc. Am. J., 59: 481-487.

Al-Taisan W, 2010. Comparative effects of drought and salt stress on germination and seedling growth of Pennisetum divisum (Gmel.) Henr.. Am. J. Applied Sci., 7: 640-646.

Benson, D.A., I. Karsch-Mizrachi, D.J. Lipman, J. Ostell and B.A. Rapp et al., 2002. GenBank. Nucleic Acids Res., 30: 17-20.

Beyer, P., S. Al-Babili, X. Ye, P. Lucca and P. Schaub et al., 2002. Golden rice: introducing the betacarotene biosynthesis pathway into rice endosperm by genetic engineering to detect vitamin A deficiency. J. Nutr., 132: 506S-510S.

Beynen A. C, F. V. Altena and E.A. Visser, 2010. Beneficial effect of a cellulose-containing chew treat on canine periodontal disease in a doubleblind, placebo-controlled trial. Am. J. Animal Vet. Sci., 5: 192-195.

Chand, J.N. and V. Pal, 1982. Citrus Canker in India and its Management. In: Problems of Citrus Diseases in India, Raychaudhuri, S.P. and Y.S. Ahlawat, (Eds.)., Surabhi, New Delhi.

Civerolo, E.L., 1981. Citrus bacterial canker disease: An overview. Proc. Int. Soc. Citric., 1: 390-394. 
Cohen, Y., 1994. 3-Aminobutyric acid induces systemic resistance against Peronospora tabacina. Physiol. Mol. Plant Pathol., 44: 273-288.

Cohen, Y., M. Reuveni and A. Baider, 1999. Local and systemic activity of BABA (DL-3- Aminobutyric acid) against Plasmopara viticola in grapevines. Eur. J. Plant Pathol., 105: 351-361.

Cohen, Y., T. Niderman, E. Mosinger and R. Fluhr, 1994. $\beta$-Aminobutyric acid induces the accumulation of pathogenesis-related proteins in tomato (Lycopersicon esculentum L.) plants and resistance to late blight infection caused by Phytophthora infestans. Plant Physiol., 104: 59-66.

Dong, H. and S.V. Beer, 2000. Riboflavin induces disease resistance in plants by activating a novel signal transduction pathway. Phytopathology, 90: 801-811.

Ghanbarpour, R. and M. Salehi, 2010. Determination of adhesin encoding genes in escherichia coli isolates from omphalitis of chicks. Am. J. Animal Vet. Sci., 5: 91-96.

Goto, M., 1992. Citrus Canker. In: Diseases of Fruit Crops-Plant Diseases of International Importance, Kumar, J., H.S. Chaube, U.S. Singh and A.N. Mukhopadhyay, (Eds.)., Prentice Hall, Englewood Cliffs.

Graham, J.H., T.R. Gottwald and R.P. Leite Jr, 2006. Prospects for control of citrus canker with novel chemical compounds. Proc. Fla. State Hort. Soc., 119: 82-88.

Graham, J.H., T.R. Gottwald, J. Cubero and D. Achor, 2004. Xanthomonas axonopodus pv. citri: Factors affecting successful eradication of citrus canker. Mol. Plant Pathol., 5: 1-15.

Han, N.M. and C.Y. May, 2010. Determination of antioxidants in oil palm leaves (Elaeis guineensis). Am. J. Applied Sci., 7: 1243-1247.

Hwang, B.K., J.Y. Sunwoo, Y.J. Kim and B.S. Kim, 1997. Accumulation of $\beta$-1,3-glucanase and chitinase isoforms and salicylic acid in the DL- $\beta$ amino-nbutyric acid-induced resistance response of pepper stems to Phytophthora capsici. Physiol. Mol. Plant Pathol., 51: 305-322.

Jakab, G., V. Cottier, V. Toquin, G. Rigoli and L. Zimmerli et al., 2001. $\beta$-Aminobutyric acidinduced resistance in plants. Eur. J. Plant Pathol., 107: 29-37.

Kumar, R.M., 2009. The widely used diagnostics "dna microarray"-a review. Am. J. Infect. Dis., 5: 207218.

Lawton, K., L. Friedrich, M., Hunt, K. Weymann. H and Kessmann 1996. Benzothiadiazole induces disease resistance in Arabidopsis by activation of the systemic acquired resistance signal transduction pahway. Plant J., 10: 71-82.
Leite Jr, R.P., S.K. Mohan, A.L.G. Pereira and C.A. Campacci, 1987. Integrated control of citrus canker: Effect of genetic resistance and application of bactericides. Fitopatol. Bra., 12: 257-263.

Madhavi, M., P. Samudram, A. HemanthKumar, and L. Victor, 2009. Effect of antioxidant vitamins C and $\mathrm{E}$ supplementation on its plasma levels and on lipid profile in pulmonary tuberculosis patients 26 . Am. J. Infect. Dis., 5: 263-272.

Mahfouz, M.H., H.M. Ghanem and M.A. Mohamed, 2010. Modulation of insulin receptor substrate-1 and some inflammatory variables in hyperinsulinemic rats treated with cinnamon extract. Am. J. Biochem. Biotechnol., 6: 11-18.

Marco, G.M. and R.E. Stall, 1983. Control of bacterial spot of pepper initiated by strains of Xanthomonas campestris pv. vesicatoria that differ in sensitivity to copper. Plant Dis., 67: 779-781.

McGuire, R.G. 1988. Evaluation of bactericidal chemicals for control of Xanthomonas on citrus. Plant Dis., 72: 1016-1020.

Mur, L.A.J., Naylor, G., Warner, S. A. J., Sugars, J. M., White, R. F. and Draper, J. (1996). Salicylic acid potentiates defence gene expression in tissue exhibiting acquired resistance to pathogen attack. Plant Journal 9, 559-571

Mur, L.A.J., Naylor, G., Warner, S.A.J., Sugars, J.M., White, R.F. and Draper, J. 1996. Salicylic acid potentiates defense gene expression in tissues exhibiting acquired resistance to pathogen attack. Plant J., 9: 559-571.

Park, D.S., J.W. Hyun, Y.J. Park, Kim. J.S. Kang, H. W., Han, J.H. and Go, S.J. 2006. Sensitive and specific detection of Xanthomonas axonopodis pv. citri by PCR using pathovar specific primers based on hrpW gene sequences. Microbiol. Res., 161: 145-149.

Pavet, V., E. Olmos, G. Kiddle, S. Mowla and S. Kumar et al., 2005. Ascorbic acid deficiency activates cell death and disease resistance response in Arabidopsis. Plant Physiol., 139: 1291-1303.

Reuveni, M., D. Sheglov and Y. Cohen, 2003. Control of moldy-core decay in apple fruits by $\beta$ aminobutyric acids and potassium phosphites. Plant Dis., 87: 933-936.

Rinaldi, D.A.M.F. and R.P. Leite Jr, 2000. Adaptation of Xanthomonas axonopodis pv. citri population to the presence of copper compounds in nature. Proc. Int. Soc. Citriculture, 2: 1064.

Roberts, M.R., 2007. Does GABA act as a signal in plants. Plant Signal Behav., 2: 408-409. 
Rojas, J.J., V.J. Ochoa, S.A. Ocampo and J.F. Munoz, 2006. Screening for antimicrobial activity of ten medicinal plants used in Colombian folkloric medicine: A possible alternative in the treatment of non-nosocomial infections. BMC Complement Altern Med., 6: 2.

Rossetti, V., 1977. Citrus canker in Latin America: A review. Proc. Int. Soc. Citric., 3: 918-924.

Sakr, H.F., 2010. Endothelial dysfunction induced by type 2 diabetes mellitus and fibrinolytic activity. Am. J. Biochem. Biotechnol., 6: 103-110.

Saeed, B.A., K.Y. Saour, R.S. Elias, N.A. AlMasoudi and P.L. Cola, 2010. Antitumor and quantitative structure activity relationship study for dihydropyridones derived from curcumin. Am. J. Immunol., 6: 7-10.

Saw, N. M.M.T., H. Riedel, O. Kütük, K. Ravichandran and I. Smetanska, 2010. Effect of elicitors and precursors on the synthesis of anthocyanin in grape vitis vinifera cell cultures. Energy Res. J., 1: 189-192.

Schaad, N.W., E. Postnikova, G. Lacy, A. Sechler and L. Garkova et al., 2006. Emended classification of xanthomonad pathogens on citrus. Syst. Applied Microbiol., 29: 90-695.

Schroder, M., K. Hahlbrock and E. Kombrink, 1992. Temporal and spatial patterns of $\beta$-1,3-glucanase and chitinase induction in potato leaves infected by Phytophthora infestans. Plant J., 2: 161-172.
Shelp, B.J., A.W. Bown and M.D. McLean, 1999. Metabolism and functions of gamma-aminobutyric acid. Trends Plant Sci., 4: 446-452.

Stall, R.E. and C.P. Seymour, 1983. Canker, a threat to citrus in the Gulf-Coast States. Plant Dis., 67: 581-585.

Ting, A.S.Y., S. W. Mah and C.S. Tee, 2010. Identification of volatile metabolites from fungal endophytes with biocontrol potential towards fusarium oxysporum F. sp. cubense Race 4. Am. J. Agric. Biol. Sci., 5: 177-182.

Thomas, E. and B.R. Kropp, 2010. Some effects of abiotic stress on infection of dyer's woad (Isatis tinctoria L.) by Puccinia thlaspeos C. Schub.: implications for biological control. Am. J. Agric. Biol. Sci., 6: 45-51.

Umebese, C.E., Olatimilehin, T. O. and Ogunsusi, T. A. 2009. Salicylic acid protects nitrate reductase activity, growth and proline in amaranth and tomato plants during water deficit. Am. J. Agric. Biol. Sci., 4: 224-229.

Zareian, P., A. Sotoodeh Jahromi, F. Hemati Rad and S. Zarei, 2010. Do resistin and tumor necrosis factor- $\alpha$ relate to changes in insulin resistance in normal pregnancy. Am. J. Biochem. Biotechnol., 6: 19-24.

Zuorro, A. and R. Lavecchia, 2010. Adsorption of $\mathrm{Pb}$ (II) on spent leaves of green and black tea. Am. J. Applied Sci., 7: 153-159. 